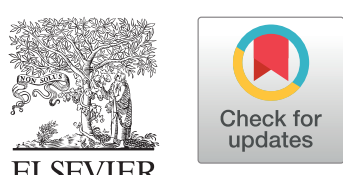

ELSEVIER

CJC Open 3 (2021) 693-694

\title{
Images in Cardiology \\ Air Bubble Trapped in the Left Atrial Appendage After Occluder Delivery
}

\author{
Alexis Hermida, MD, Maciej Kubala, MD, PhD, and Jean-Sylvain Hermida, MD \\ Cardiac Arrhythmia Service, Amiens-Picardie University Hospital, Amiens, France
}

\section{Case}

A 79-year-old woman was referred to our centre for left atrial appendage (LAA) occlusion. She had permanent atrial fibrillation and experienced bleeding while being treated with rivaroxaban. Her Congestive Heart Failure, Hypertension, Age ( $\geq 75$ years), Diabetes, Stroke/Transient Ischemic Attack, Vascular Disease, Age (65-74 years), Sex (Female) $\left(\mathrm{CHA}_{2} \mathrm{DS}_{2}\right.$ VASc) score was 9 (congestive heart failure, hypertension, age, diabetes mellitus, stroke, vascular disease, female).

Transseptal access was achieved, guided by transesophageal echocardiography. We then introduced the occluder delivery system into the left atrium, without difficulty. The system was perfused with saline with an autopump. Contrast was injected into the LAA (Fig. 1). After delivery of the device, contrast was injected again. Just after, we clearly visualized an air bubble trapped in the LAA (Fig. 2). We provide a video showing the bubble moving into the LAA (Video 1 品... view view video online). We immediately examined the delivery system and noted that the valve was unclipped from the delivery sheath. We had to push strongly to correctly reclip it. The transesophageal echocardiography did not show any flow from the LAA after device placement.

We finished the procedure and tried to once again unclip the valve, which proved to be impossible. We conclude that the system had a manufacturing defect.

Our patient did not experience an ischemic event in relation to this accident. Forty-eight hours later, we performed an $\mathrm{x}$-ray and noted the spontaneous disappearance of the bubble.

\section{Novel Teaching Points}

- An air bubble trapped in the left atrial appendage can disappear spontaneously.

- Careful examination of the material integrity of the device is needed before starting any percutaneous procedure.

This case, which could have ended badly, is a reminder that the material integrity of devices must be verified before starting a procedure.

\section{Funding Sources}

The authors report no funding sources.

\section{Disclosures}

The authors have no conflicts of interest to disclose.

\section{Supplementary Material}

To access the supplementary material accompanying this article, visit CJC Open at https:/www.cjcopen.ca/ and at https://doi.org/10.1016/j.cjco.2021.01.002.

Received for publication November 20, 2020. Accepted January 5, 2021.

Ethics Statement: The research reported has adhered to the relevant ethical guidelines.

Corresponding author: Dr Alexis Hermida, Amiens-Picardie University Hospital, 1 Rond-Point du Pr Christian Cabrol, 80054 Amiens Cedex 1, France. Tel.: +33-322-45-58-75; fax: +33-322-45-56-58.

E-mail: a.hermida.jarry@gmail.com

See page 693 for disclosure information. 


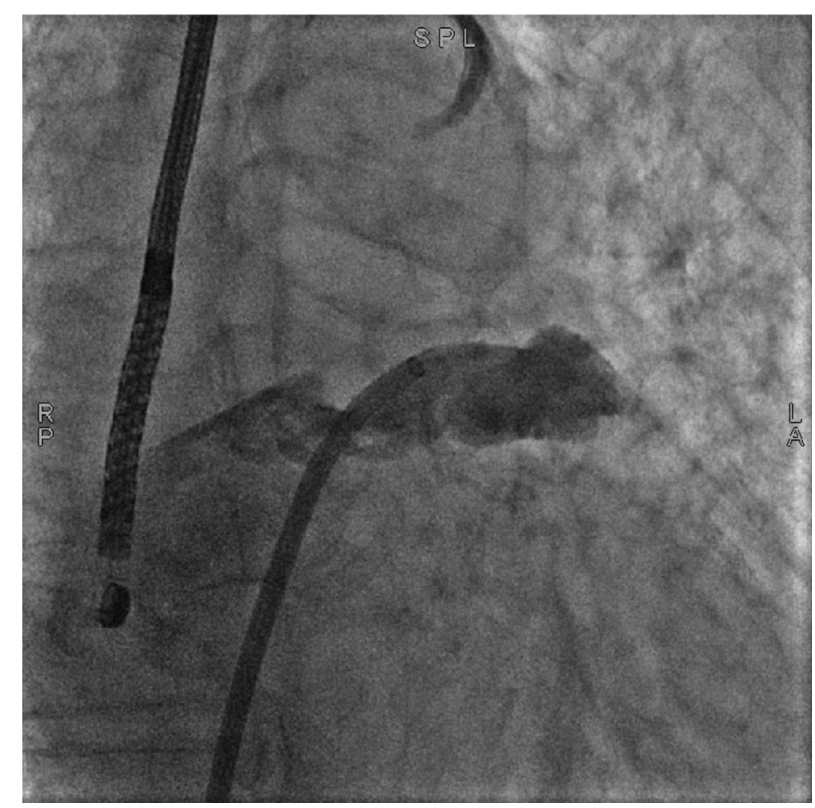

Figure 1. Angiographic image of the left atrial appendage.

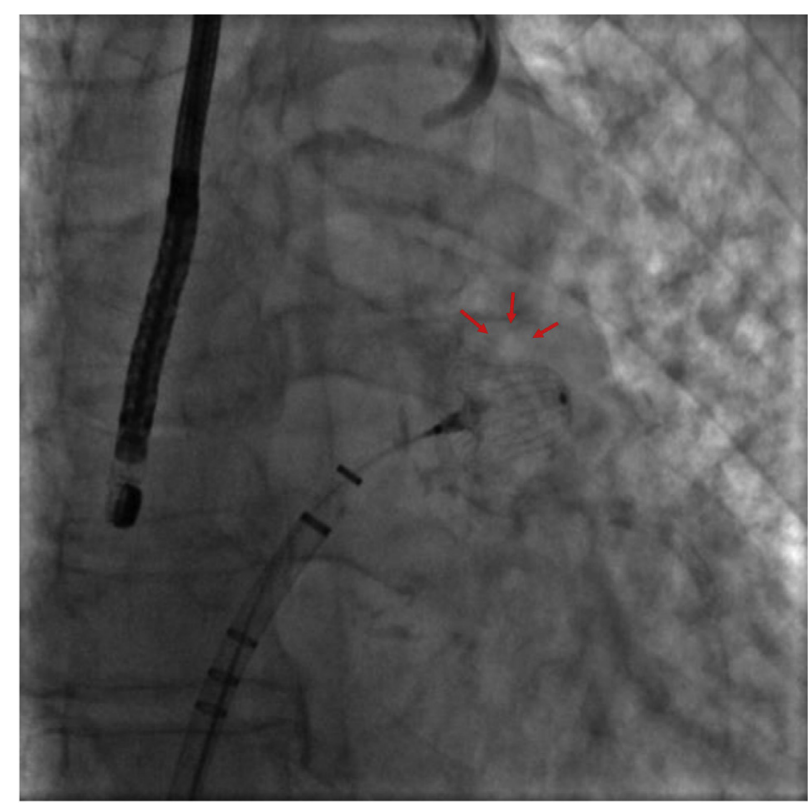

Figure 2. Air bubble trapped in the left atrial appendage. (Red arrows) point the bubble. 